\title{
Perencanaan Lean Manufacturing Untuk Mengurangi Pemborosan Menggunakan Metode Value Stream Mapping Pada PT Y Indonesia
}

\begin{abstract}
S. Aisyah
Abstrak - PT Y Indonesia merupakan perusahaan yang bergerak pada bidang otomotif khususnya spark plug (busi) dan plug cap. Perusahaan berupaya untuk meningkatkan produktivitas dengan cara mengurangi pemborosan yang terjadi. Untuk mengetahui pemborosan yang ada pada PT Y Indonesia dilakukan penelitian dengan menggunakan metode Value Stream Mapping (VSM). Data awal pemborosan didapatkan dari kuesioner yang diberikan kepada 3 orang yang mempunyai kapabilitas untuk menjawab pertanyaan yang ada. Dari hasil perhitungan yang didapat maka pemborosan di proses produksi yang didapatkan berdasarkan kegiatan yang bernilai tambah (VA) sebesar 4\%, lalu untuk NNVA mendapatkan persentase sebesar 10\% dan untuk kegiatan yang tidak memberikan nilai tambah (NVA) mendapatkan persentase sebesar 86\%. Penyebab tingginya persentas kegiatan yang tidak memiliki nilai tambah adalah akibat delay yang telalu lama pada saat proses produksi. Berdasarkan hasil diatas maka perusahaan memerlukan tindakan yang tepat untuk mengurangi delay yang terjadi pada saat proses produksi dengan melakukan pengawasan berkala pada saat proses produksi sedang berlangsung dan membuat jadwal waktu pergantian operator dalam bekerja.
\end{abstract}

Kata Kunci- Produktivitas, Pemborosan, Value Stream Mapping (VSM)

Abstract - PT Y Indonesia is a company engaged in the automotive sector, especially spark plugs (plugs) and plug cap. The company strives to increase productivity by reducing waste that occurs. To find out the waste that is in PT Y Indonesia, the research was conducted using the Value Stream Mapping (VSM) method. Proverbial waste data is obtained from questionnaires given to 3 people who have the capability to answer existing questions. From the calculation results obtained, waste in the production process obtained based on activities that are added value (VA) of 4\%, then for NNVA get a percentage of $10 \%$ and for activities that do not provide added value (NVA) get a percentage of $86 \%$. The cause of the high percentage of activities that do not have added value is the result of delays that are too long during the production process. Based on the results above, the company requires appropriate action to reduce the delay that occurs during the production process by conducting periodic supervision while the production process is underway and brainstorming to increase operator productivity

Keywords — lean manufacturing, value stream mapping, waste, value stream analysis tools

\section{PENDAHULUAN}

Seiring dengan perkembangan dunia industri saat $\mathcal{N}_{\text {ini, kompetisi antar perusahaan manufaktur }}$ sangat ketat baik perusahaan nasional maupun multinasional. Memaksimalkan produktivitas perusahaan agar tercapainya target perusahaan baik dari segi kualitas, harga yang terjangkau dan ketepatan waktu yang sesuai dengan permitaan pelanggan adalah hal yang mutlak. Perusahaan harus memaksimalkan dan mengoptimalkan sumber daya yang ada, serta melakukan improvemet guna meningkatkan produktivitas perusahaan.

Lean Manufacturing merupakan suatu konsep yang awalnya dikembangkan oleh Toyota, kemudian dikenal sebagai Just - In - Time Manufacturing.

Siti Aisyah, Mahasiswa Program Studi Teknik Industri, Universitas Indraprasta PGRI, Jakarta (staisyahh25@gmail.com)
Konsep Lean Manufacturing bertujuan untuk mengubah suatu organisasi di perusahaan menjadi lebih efisien dan kompetitif. Aplikasi dari konsep Lean Manufacturing yaitu mengurangi lead time dan meningkatkan output dengan menghilangkan pemborosan yang terjadi di sebuah perusahaan ${ }^{[5]}$. Toyota telah mengidentifikasikan tujuh jenis aktivitas utama yang tidak memiliki nilai tambah dalam bisnis atau proses manufaktur serta dapat digunakan pada pengembangan produk dan penerimaan pesanan, tidak hanya di jalur produksi. Berikut adalah tujuh jenis aktivitas yang tidak bernilai tambah bagi perusahaan yaitu: produksi berlebihan, menunggu, transportasi, pemrosesan secara berlebih, persediaan berlebih, gerakan yang tidak perlu dan produk cacat [1].

PT Y Indonesia merupakan perusahaan yang 
bergerak di bidang manufaktur otomotif, yang memproduksi Spark Plug (busi) dan Plug Cap dalam berbagai tipe dan berbagai kemasan sesuai dengan permintaan pelanggan. Kendala yang dihadapi perusahaan adalah rendahnya produktivitas produksi yang menyebabkan terjadinya overtime, tetapi kapasitas produksi sebenarnya cukup untuk produksi. Pada penelitian terdahulu yang telah dilakukan oleh Fernando dan Noya di PT Bonindo Abadi tahun 2014 mengenai Value Stream Mapping (VSM) didapatkan bahwa dengan menggunakan Value Stream Mappping (VSM) perusahaan dapat mengurangi jumlah waktu yang tidak bernilai tambah [2].

Penelitian ini dilakukan dengan menggunakan Value Stream Mapping untuk melihat pemborosan yang terjadi dengan menggunakan Value Stream Analysis Tools (VALSAT) dan menganalisa masalah pemborosan yang terjadi dengan menggunakan FMEA (Failure Mode and Effect Analyze) untuk meminimasi semua kegagalan-kegagalan yang potensial serta memberikan usulan perbaikan kepada perusahaan yang dapat dijadikan pertimbangan dalam meningkatkan produktivitas produksi, sehingga perusahaan dapat mencapai nilai yang ingin dicapai oleh perusahaan.

\section{METODE DAN PROSEDUR}

Metodologi penelitian adalah langkah-langkah untuk melakukan penelitian pada PT Y Indonesia. Berikut adalah langkah penelitian dapat dilihat pada Gambar 1.

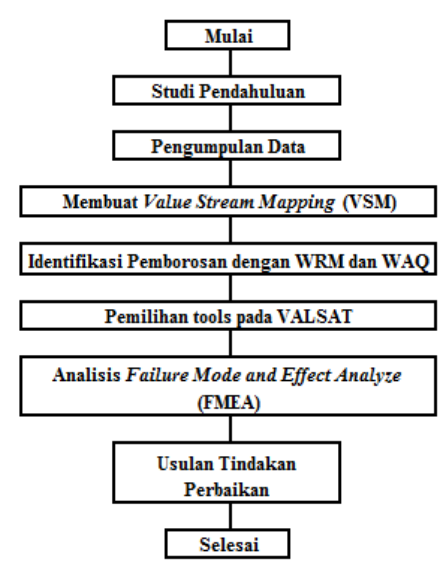

Gambar 1. Langkah-Langkah Penelitian

1. Studi Pendahuluan

Studi pendahuluan dilakukan dengan mencari literatur dari buku, skripsi dan jurnal yang berhubungan dengan penelitian agar mendapatkan pemahaman teoritis tentang pembahasan dalam penelitian.

2. Pengumpulan Data

Data-data yang dikumpulkan sebagai bahan penelitian adalah data kuesioner tentang pemborosan, data hasil wawancara, data waktu pemesanan dan pengiriman barang, data permintaan aktual, data Output dan data kapasitas produksi pada periode 2017-2018.

3. Pengolahan Data

a. Value Stream Mapping (VSM)

Melakukan Pembuatan Value Stream Mapping jenis Current State Map (Peta saat ini) untuk megetahui keadaan alur proses informasi saat ini.

b. Waste Relationship Matrix (WRM) dan Waste Assesment Questionnaire (WAQ)

Waste Relationship Matrix digunakan untuk menganalisis kriteria pengukuran dan Waste Assesment Questionnaire digunakan untuk mengidentifikasikan peemborosan yang terjadi pada jalur produksi.

c. Value Stream Analysis Tools (VALSAT)

Menentukan tools yang akan digunakan untuk dilakukan analisis. Terdapat 7 tools yaitu: Process Activity Mapping, Supply Chain Response Matrix, Production Variety Funnel, Quality Filter Mapping, Demand Amplication Mapping, Decision Point Analysis dan Physical Structure. ${ }^{[4]}$

d. Failure Mode and Effect Analyze (FMEA)

Setelah ketahui pemborosan terbesar maka dilakukan analisis menggunakan FMEA untuk mengetahui nilai RPN ( Risk Priority Number) tertinggi yang akan menjadi prioritas utama untuk melakukan perbaikan.

\section{Usulan Perbaikan}

Setalah diketahui pemborosan yang akan menjadi prioritas untuk perbaikan, maka dilakukan pemberian beberapa usulan perbaikan untuk mengurnagi pemborosan yang ada.

\section{III.HASIL DAN PEMBAHASAN}

Berdasarkan pengumpulan dan pengolahan data maka didapatkan hasil: 


\section{Current State Mapping}

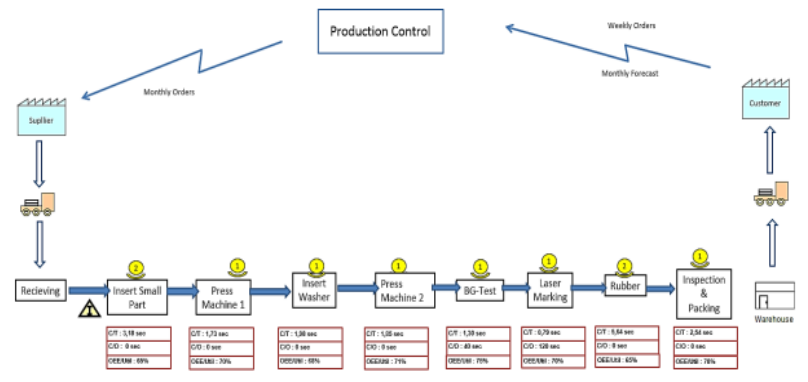

Gambar 2. Current State Map

Pada Gambar 2 menunjukkan alur proses informasi pada PT Y Indonesia waktu pengerjaan setiap stasiun kerja, jumlah pekerja yang bekerja pada tiap stasiun kerja, OEE setiap stasiun kerja. Dari hasil current state mapping yang telah dibuat dapat diketahui bahwa waktu pengerjaan pada setiap stasiun kerja tidak terlalu jauh tetapi output yang didapatkan tidak sesuai dengan kemampuan mesin.

\section{Waste Relationship Matrix (WRM)}

Berikut adalah Tabel 1 hubungan setiap pemborosan dimana $\mathrm{O}$ adalah Overtime, I (Inventory), $\quad \mathrm{D}$ (Defect), $\mathrm{M}$ (Motion), $\mathrm{T}$ (Transportation), P (Process) dan W (Waiting).

Tabel 1. Waste Relationship Matrix (WRM)

\begin{tabular}{cccccccc}
\hline F/T & O & I & D & M & T & P & W \\
\hline O & A & I & O & I & I & X & O \\
I & I & A & I & I & O & X & X \\
D & E & I & A & E & O & X & O \\
M & O & I & I & A & X & E & I \\
T & I & O & O & A & A & X & I \\
P & O & O & E & A & X & A & I \\
W & O & I & I & X & X & X & A \\
\hline
\end{tabular}

Langkah selanjutnya adalah membuat Waste Matrix Value dengan mengkonversi simbol-simbol diatas dengan pemberian skor $\mathrm{A}=10, \mathrm{E}=8, \mathrm{O}=4$, $\mathrm{U}=2$ dan $\mathrm{X}=0{ }^{[3]}$ Berikut adalah nilai hasi Waste Matrix Value.

Tabel 2. Waste Matrix Value

\begin{tabular}{cccccccccc}
\hline F/T & $\mathbf{O}$ & $\mathbf{I}$ & $\mathbf{D}$ & $\mathbf{M}$ & $\mathbf{T}$ & $\mathbf{P}$ & $\mathbf{W}$ & $\mathbf{S k o r}$ & $\mathbf{\%}$ \\
\hline $\mathbf{O}$ & 10 & 6 & 4 & 6 & 6 & 0 & 4 & 36 & 14,17 \\
$\mathbf{I}$ & 6 & 10 & 6 & 6 & 4 & 0 & 0 & 32 & 12,60 \\
$\mathbf{D}$ & 8 & 6 & 10 & 8 & 4 & 0 & 4 & 40 & 15,75 \\
$\mathbf{M}$ & 4 & 6 & 6 & 10 & 0 & 6 & 6 & 38 & 14,96 \\
$\mathbf{T}$ & 6 & 4 & 4 & 10 & 10 & 0 & 6 & 40 & 15,75 \\
$\mathbf{P}$ & 4 & 4 & 8 & 10 & 0 & 10 & 6 & 42 & 16,54 \\
$\mathbf{W}$ & 4 & 6 & 6 & 0 & 0 & 0 & 10 & 26 & 10,24 \\
Skor & 42 & 42 & 44 & 50 & 24 & 16 & 36 & 254 & 100 \\
$\mathbf{\%}$ & 16,54 & 15,54 & 17,32 & 19,69 & 9,45 & 6,30 & 14,17 & & \\
\hline
\end{tabular}

Berdasarkan Tabel 2 dapat diketahui bahwa Setelah dilakukan perhitungan dari hasil pembobotan kuesioner maka didapatkan presentase pemborosan dari kolom "from" yaitu Process yang bernilai $16,54 \%$ dan pemborosan yang berasal dari kolom "to" yaitu Motion yang bernilai $19,69 \%$.

\section{Waste Assessment Questionnaire (WAQ)}

Tabel 3. Hasil Perhitungan Waste Assessment Questionnaire

\begin{tabular}{lccccccc}
\hline & O & I & D & M & T & P & W \\
\hline Skor Yj & 3,14 & 3,64 & 3,59 & 3,23 & 3,13 & 3,60 & 3,31 \\
Pj Faktor & 234 & 208 & 272 & 294 & 148 & 104 & 145 \\
Hasil Akhir & 734,70 & 757,57 & 977,12 & 948,93 & 462,71 & 374,20 & 479,43 \\
\% & 15,52 & 16 & 20,64 & 20,04 & 9,77 & 7,90 & 10,13 \\
Peringkat & 4 & 3 & 1 & 2 & 6 & 7 & 5 \\
\hline
\end{tabular}

Berdasarkan Tabel 3 bahwa untuk menghitung nilai untuk setiap pemborosan ( $\mathrm{Yj}$ Final) harus mengetahui indikator awal untuk setiap pemborosan $(\mathrm{Yj})$ dan nilai probabilitas untuk masing-masing pemborosan ( $\mathrm{Pj})$. Hasil persentase yang didapat pada Waste Assessment Questionnaire maka akan digunakan sebagai bobot awal dalam Value Stream Analysis Tools (VALSAT) dengan mengkalikan bobot awal pemborosan yang terjadi dengan faktor-faktor yang telah ditentukan. Berikut adalah hasil nilai yang telah didapat dengan menggunakan Value Stream Analysis Tools (VALSAT).

Tabel 4. Value Stream Analysis Tools Matrix

\begin{tabular}{|c|c|c|c|c|c|c|c|c|}
\hline & & \multicolumn{7}{|c|}{ Seven Mapping Tools } \\
\cline { 3 - 9 } & $\begin{array}{c}\text { Weig } \\
\text { ht }\end{array}$ & $\begin{array}{c}\text { Process } \\
\text { Activity } \\
\text { Mapping }\end{array}$ & $\begin{array}{c}\text { Supply } \\
\text { Chain } \\
\text { Respon } \\
\text { se } \\
\text { Matrix }\end{array}$ & $\begin{array}{c}\text { Produc } \\
\text { tion } \\
\text { Variety } \\
\text { Funnel }\end{array}$ & $\begin{array}{c}\text { Quality } \\
\text { Fitter } \\
\text { Mapping }\end{array}$ & $\begin{array}{c}\text { Demand } \\
\text { Amplication } \\
\text { Mapping }\end{array}$ & $\begin{array}{c}\text { Decision } \\
\text { Point } \\
\text { Analysis }\end{array}$ & $\begin{array}{c}\text { Physical } \\
\text { Structur } \\
\boldsymbol{e}\end{array}$ \\
\hline $\begin{array}{c}\text { Over } \\
\text { Production }\end{array}$ & 15,52 & 15,52 & 46,56 & & 15,52 & 46,56 & 46,56 & \\
\hline Waiting & 16 & 144 & 144 & 16 & & 48 & 48 & 20,64 \\
\hline Transportation & 20,64 & 185,76 & & & & & & \\
\hline $\begin{array}{c}\text { Over } \\
\text { processing }\end{array}$ & 20,04 & 180,36 & & 60,12 & 20,04 & & 20,04 & \\
\hline Inventory & 9,77 & 29,31 & 87,93 & 29,31 & & 87,93 & 29,31 & 9,77 \\
\hline Motion & 7,90 & 71,10 & 7,9 & & & & & \\
\hline Defect & 10,13 & 10,13 & & & 91,17 & & & \\
\hline Total & & $\mathbf{6 3 6 , 1 8}$ & $\mathbf{2 8 6 , 3 9}$ & $\mathbf{1 0 5 , 4 3}$ & $\mathbf{1 2 6 , 7 3}$ & $\mathbf{1 8 2 , 4 9}$ & $\mathbf{1 4 3 , 9 1}$ & $\mathbf{3 0 , 4 1}$ \\
\hline
\end{tabular}

Berdasarkan Tabel 4 dapat diketahui bahwa dari tujuh alat pemetaan ${ }^{[4]}$ yang mendapat nilai terbesar adalah Process Activity Mapping dimana mendapatkan nilai 636,18 , maka dari itu tools ini dipilih untuk mengidentifikasi dan menganalisis pemborosan yang terjadi pada proses produksi pada PT Y indonesia.

\section{Process Activity Mapping}

Langkah selanjutnya dalam Process Activity Mapping (PAM) adalah melakukan pengeolompokkan pekerjaan berdasarkan kegiatannya yaitu: operasi, transportasi, 
pemeriksaan, penyimpanan, dan keterlambatan (menunggu). Selain itu pula terdapat 3 tipe aktivitas yang terjadi dalam proses produksi yaitu Value Added (VA), Necessary Non Value Added (NNVA) dan yang terakhir yaitu Non Value Added (NVA). Berikut adalah grafik hasil Process Activity Mapping (PAM).

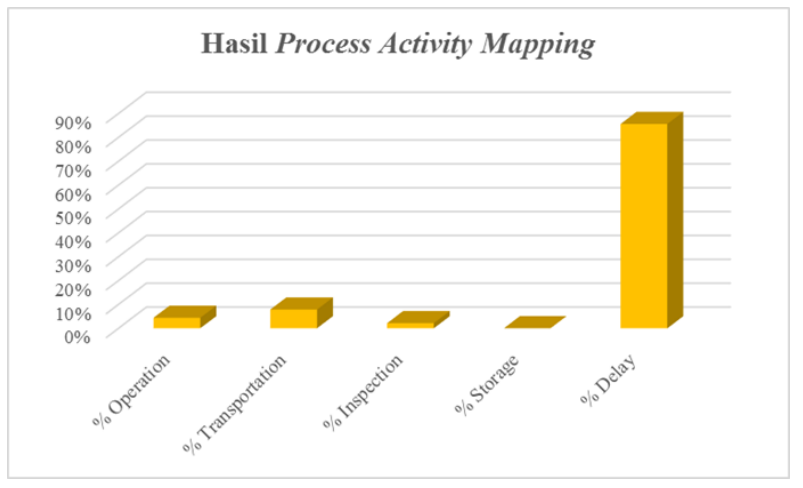

Gambar 3. Grafik Hasil Process Activity Mapping

Berdasarkan Gambar 3 didapatkan bahwa pada proses produksi PT Y Indonesia tidak produktif dan menghasilkan kegiatan yang tidak bernilai tambah yaitu delay sebesar $86 \%$. Delay ini disebabkan oleh waktu menunggu untuk beberapa proses karena dibutuhkannya banyak unit dalam sekali pemeriksa apabila terjadi kebocoran pada Plug Cap dengan menggunakan mesin BG-Test dan proses Laser Marking, yang digunakan untuk memberikan kode pada setiap Plug Cap.

\section{Failure Mode and Effect Analyze (FMEA)}

Tabel 5. Failure Mode Effect Analysis

\begin{tabular}{|c|c|c|c|c|c|c|c|c|c|}
\hline 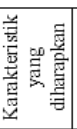 & के & bั & 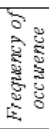 & 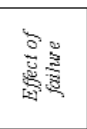 & 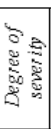 & 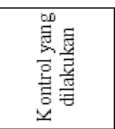 & 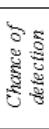 & 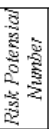 & 芠 \\
\hline \multirow{4}{*}{ 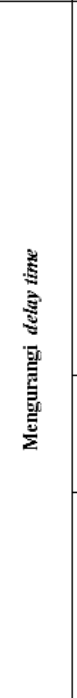 } & \multirow{2}{*}{ Manusia } & $\begin{array}{c}\text { Tidak } \\
\text { adanya } \\
\text { jadwal } \\
\text { pergantian } \\
\text { operator } \\
\text { yang tetap }\end{array}$ & 7 & $\begin{array}{c}\text { Operator } \\
\text { berganti } \\
\text { an secara } \\
\text { random } \\
\text { dan } \\
\text { menyeba } \\
\text { bkan } \\
\text { delay } \\
\end{array}$ & 8 & $\begin{array}{c}\text { Adanya } \\
\text { standar jam } \\
\text { pergantian } \\
\text { operator dan } \\
\text { di } \\
\text { intruksikan } \\
\text { oleh leader }\end{array}$ & 1 & 56 & 2 \\
\hline & & $\begin{array}{c}\text { Kurang- } \\
\text { nya } \\
\text { pengawasa } \\
\text { n }\end{array}$ & 8 & $\begin{array}{c}\text { Operator } \\
\text { sering } \\
\text { bercanda } \\
\text { saat } \\
\text { proses } \\
\text { produksi } \\
\text { berlangs } \\
\text { ung } \\
\end{array}$ & 8 & $\begin{array}{c}\text { Leader dan } \\
\text { Supervisor } \\
\text { harus sering } \\
\text { melakukan } \\
\text { pengawasan }\end{array}$ & 1 & 64 & 1 \\
\hline & Mesin & $\begin{array}{c}\text { Terdapat } \\
\text { beberapa } \\
\text { mesin } \\
\text { sudah tua }\end{array}$ & 3 & $\begin{array}{c}\text { Aliran } \\
\text { proses } \\
\text { produksi } \\
\text { tidak } \\
\text { lancar } \\
\end{array}$ & 4 & $\begin{array}{c}\text { Melakukan } \\
\text { pemeriksaan } \\
\text { berkala }\end{array}$ & 1 & 12 & 4 \\
\hline & Material & $\begin{array}{c}\text { Ukuran } \\
\text { material } \\
\text { yang kecil }\end{array}$ & 3 & $\begin{array}{c}\text { Terjadin } \\
\text { ya } \\
\text { double } \\
\text { insert } \\
\text { material } \\
\text { saat } \\
\text { proses } \\
\text { produk }\end{array}$ & 3 & $\begin{array}{c}\text { Adanya } \\
\text { sensor } \\
\text { untuk } \\
\text { mendeteksi } \\
\text { apakah } \\
\text { material } \\
\text { yang } \\
\text { dimasukkan } \\
\text { sudah sesuai }\end{array}$ & 5 & 45 & 3 \\
\hline
\end{tabular}

Berdasarkan Tabel 5 hasil FMEA yang telah diolah didapatkan bahwa penyebab terbesar terjadinya delay adalah kesalahan dari manusia, dimana kurangnya pengawasan dari leader yang menyebabkan operator masih santai dalam mengerjakan pekerjaannya dan tidak adanya jadwal pergantian operator yang menyebabkan operator melakukan pergantian secara random dan menyebabkan delay pada stasiun kerja operator tersebut

\section{IV.SIMPULAN}

Berdasarkan penelitian yang dilakukan pada PT Y Indonesia dapat disimpulkan bahwa tools yang digunakan untuk menganalisis pemborosan yang terjadi adalah PAM, dimana hasil yang didapatkan adalah hanya $4 \%$ kegiatan yang bernilai tambah (VA), 10\% untuk kegiatan yang dibutuhkan tapi tidak bernilai tambah (NNVA) dan $86 \%$ untuk kegiatan yang tidak bernilai tambah (NVA). Banyaknya persentase kegiatan yang tidak bernilai tambah disebabkan oleh lamanya waktu menunggu pada beberapa stasiun kerja yang disebabkan oleh lambatnya operator pada stasuin kerja sebelumnya.

Usulan perbaikan yang diberikan kepada perusahaan berdasarkan dari identifikasi penyebab pemborosan adalah perlunya pengawasan berkala untuk melihat kinerja operator dan diperlukannya jadwal waktu pergantian operator agar tidak ada pergantian operator secara random.

\section{DAFTAR PUSTAKA}

[1] K, L. Jeffrey dan D. Meier, 2007. The Toyota Way Fieldbook: Panduan untuk mengimplementasikan model $4 P$ toyota. diterjemahkan oleh : Penerbit Erlangga, Jakarta

[2] Y. C. Fernando, dan S. Noya, 2014. Optimalisasi Lini Produksi Dengan Value Stream Mapping dan Value Stream Analysis Tools, No.2, Vol.13, 126-133, http://journals.ums.ac.id/index.php/jiti/article/view/63 0

[3] I. A. Rawabdeh, 2005. A model for the assessment of waste in job shop environments, International Journal of Operations \& Production Management. Vol.25 issue 8.

[4] P. Hines, dan N. Rich, 1997. The Seven Value Stream Mapping Tools. International Journal of Operational and Production Management. Vol.17 No. 1.

[5] T. Ristyowati, M. Ahmad, dan P. N. Putri, 2017. Minimasi Waste Pada Aktivitas Proses Produksi Dengan Konsep Lean Manufacturing (Studi Kasus Di PT. Sport Glove Indonesia). Jurnal OPSI. Vol.10, No.1. 